\title{
Análise da política pública municipal de fomento ao cooperativismo no Município de Gurupi-TO
}

\section{Analysis of the municipal public policy to cooperativism development in the municipality of Gurupi-TO, brazil}

Kárita Carneiro Pereira Scotta ${ }^{1}$, Airton Cardoso Cançado²

\section{RESUMO}

Este trabalho tem como objetivo analisar a política pública municipal de fomento ao cooperativismo, entre os anos de 2013 e 2017, no município de Gurupi-TO. Os objetivos específicos foram: 1) Avaliar a política pública municipal para 0 cooperativismo em Gurupi-TO com base na percepção dos gestores públicos, dirigentes e beneficiários em relação ao desempenho qualitativo da política pública municipal e 2) Identificar os desafios e propor diretrizes para a consolidação da gestão da política pública de fomento ao cooperativismo no município de Gurupi-TO. Trata-se de uma pesquisa de abordagem qualitativa, com coleta de dados via pesquisa bibliográfica e de documental e realização de entrevistas semiestruturadas com exgestores e dirigente que participaram e participam da condução da referida política e com os beneficiários (pequenos produtores da agricultura familiar). Os dados coletados foram categorizados e submetidos à análise de conteúdo. Portanto, vislumbrou a convergência dos interesses da gestão pública com o cooperativismo local com destaque de elementos que podem contribuir para a consolidação da política pública de fomento ao cooperativismo em Gurupi-TO por meio da avaliação política considerando os aspectos da legitimidade do processo de elaboração das ações, a percepção dos beneficiários da política pública com a indicação dos benefícios e impactos na condução da política pública de fomento ao cooperativismo local.

Palavras-chave: Cooperativismo. Gestão de Políticas Públicas. Análise de Política Pública Municipal.

\section{ABSTRACT}

This research aims to analyze the municipal public policy to promote cooperativism between 2013 and 2017, in the municipality of Gurupi-TO. The specific objectives were: 1) Evaluate municipal public policy for cooperatives in Gurupi-TO based on the perception of public managers, managers and beneficiaries in relation to the qualitative performance of the municipal public policy and 2) Identify the challenges and propose guidelines for the consolidation of the management of public policy to foster cooperativism in the municipality of Gurupi-TO. This is a qualitative research, with data collection through bibliographical and documentary research and semistructured interviews with ex-managers and managers who participated in and participated in the conduct of this policy and with the beneficiaries (small producers of family agriculture). Therefore, he envisaged the convergence of public management interests with local cooperativism, highlighting elements that may contribute to the consolidation of the public policy of fomenting cooperativism in Gurupi-TO by means of the political evaluation considering the aspects of the legitimacy of the process of elaboration of the actions, the perception of the beneficiaries of the public public policy with the indication of the benefits and impacts in the conduct of the public policy of foment to the cooperativism.

Keywords: Cooperativism. Public Policy Management. Analysis of Municipal Public Policy.
${ }^{1}$ Mestra em Gestão de Políticas Públicas (2018) pela Universidade Federal do Tocantins, Brasil. Professora da Universidade de Gurupi-TO, Brasil e da Universidade Estadual do Tocantins, Brasil.

E-mail:

karitacarneiropereira@gmail.com

2 Doutor em Administração pela Universidade Federal de Lavras, Brasil (2011). Professor Adjunto da Universidade Federal do Tocantins, Brasil.

E-mail:

airtoncardoso@yahoo.com.br 


\section{INTRODUÇÃO}

O presente trabalho possui abrangência local, visto que a nuance de investigação visa abordar a construção e condução da política pública de fomento ao cooperativismo do município de Gurupi-TO. O município está localizado ao sul do Estado às margens da BR-153, sendo o terceiro maior em contingente populacional do Estado do Tocantins, com população estimada, em julho de 2017, de 86.647 habitantes (IBGE, 2017).

No Brasil, existem políticas públicas que nascem tal como a teoria prevê, ou seja, se iniciando por um amplo processo de diagnóstico da situação a ser tratada, passando por uma fase de planejamento, pelo estabelecimento de diretrizes, pela definição do modelo de implementação, pela realização de testes, pela implantação propriamente dita da política e, por fim, pela sua avaliação e monitoramento, entre outras fases (DIAS, 2012; FREY, 2000). Entretanto, o surgimento de políticas públicas, que não consideram várias dessas importantes etapas é algo que acontece com frequência.

O que se verifica, em síntese, é que os modelos descritores do ciclo de políticas públicas raramente refletem a real dinâmica de uma política pública (SECCHI, 2010). De um modo geral o processo de uma política pública é incerto, sendo pouco nítidas as fronteiras entre suas diversas fases, sendo que estas se apresentam sobrepostas, e algumas etapas se antecipam a outras.

Em muitos casos, as políticas públicas podem surgir para tratar dos problemas existentes identificados, sem considerar a fundo as causas desses problemas. Nem sempre o governo possui tempo hábil para efetuar um adequado processo de planejamento de suas políticas.

Assim, o estudo adequado sobre o processo de implantação de uma política não é suficientemente realizado, colocando em xeque a qualidade do gasto e investimento público em geral, que diz respeito ao contexto e a forma pela qual as políticas públicas são formuladas, implementadas e avaliadas.

Diante dessas observações, torna-se necessário explicitar que este estudo é voltado para a gestão de políticas públicas na construção/condução de políticas públicas para o fomento do cooperativismo.

Por esse motivo, se propõe a avaliar a política pública municipal de fomento ao cooperativismo, no município de Gurupi-TO a fim de orientar as ações de governança, com vistas a contribuir para a formação de um ambiente mais seguro e favorável para que as políticas públicas apresentem resultados efetivamente transformadores, à altura das 
expectativas da sociedade e na concretização dos direitos sociais, previstos na Carta Magna - Constituição Federal de 1988.

A pesquisa parte da seguinte problemática: Quais os desafios e possibilidades da gestão de políticas públicas e do cooperativismo para sua consolidação no município de Gurupi-TO? Para tanto, buscará demonstrar a convergência dos interesses entre a gestão de políticas públicas e o cooperativismo para a efetiva consolidação da política municipal de fomento ao cooperativismo no município de Gurupi-TO.

As cooperativas vão além dos padrões de políticas de responsabilidade social adotadas pelas empresas mercantis, uma vez que "a participação democrática e a educação cooperativista pretendem construir novas relações entre as pessoas, o que também repercutiria na comunidade, contribuindo, assim, para o desenvolvimento e a promoção da cidadania" (MILAGRES; AMODEO e SOUZA, 2011, p.72).

Desta forma, tem-se como objetivo geral a análise da política pública municipal de fomento ao cooperativismo nos anos de 2013 a 2017 da gestão pública no município de Gurupi-TO. E como objetivos específicos os seguintes: 1) Avaliar a política pública municipal para o cooperativismo em Gurupi-To com base na percepção dos gestores públicos, dirigentes e beneficiários em relação ao desempenho qualitativo da política pública municipal e 2) Identificar os desafios e possibilidades para a consolidação da gestão na política pública de fomento ao cooperativismo no município de Gurupi-TO.

A pesquisa se justifica pela pouca densidade de trabalhos científicos sobre gestão de políticas públicas em âmbito municipal, especialmente em municípios do Estado do Tocantins, pretendendo contribuir no aspecto teórico para os atores políticos e sociais envolvidos com o cooperativismo e com a gestão de políticas públicas.

A parte metodológica traz uma abordagem qualitativa, com coleta de dados via pesquisa bibliográfica e de documental e realização de entrevistas semiestruturadas com ex-gestores e dirigente que participaram e participam da condução da referida política e com os beneficiários (pequenos produtores da agricultura familiar). Os dados coletados foram categorizados e submetidos à análise de conteúdo.

O trabalho está estruturado em 06 seções, contando com essa introdução. A segunda seção descreve a metodologia empregada na pesquisa e forma de coleta e análise dos dados.

A terceira seção versa sobre a definição conceitual de políticas públicas, abordando a importância dessa área de conhecimento suas delimitações conceituais, as tipologias, os ciclos e a avaliação das políticas públicas. 
A quarta seção trata do cooperativismo, estabelecendo a evolução histórica e o atual estado dos princípios cooperativistas, o cooperativismo no Brasil, no Estado do Tocantins e no município de Gurupi-TO, conceituando e diferenciando o cooperativismo tradicional e o cooperativismo popular. Na quinta seção traz a análise e discussão dos resultados e por fim, na sexta seção são apresentadas as considerações finais do estudo.

\section{MATERIAIS E METODOS}

Trata-se de uma pesquisa de abordagem qualitativa, por meio do método dedutivo, de caráter compreensivo, explicativo, pensando-se na avaliação com conotação política da política pública municipal de fomento ao cooperativismo no município de Gurupi-TO.

A pesquisa se dividiu em três etapas básicas: na primeira desenvolveram-se as pesquisas documental e bibliográfica; na segunda utilizou-se a técnica de coleta dados (neste estudo adotou-se a entrevista semiestruturada utilizando as técnicas bola de neve e saturação teórica); e na terceira e última etapa, consistiu na análise dos dados, utilizando como suporte a técnica de análise de conteúdo de Bardin (2016). Ambos evidenciaram as categorias de avaliação na construção do resultado da pesquisa.

Tendo definido o problema, os objetivos da pesquisa original e a metodologia a ser empregada, partiu, portanto para a coleta dos dados da pesquisa.

A coleta de dados documentais, consiste em pesquisa bibliográfica e de documentação, ou seja, busca de leis e modelos de políticas públicas de enfrentamento existentes no país, em seus bancos de dados governamentais e institucionais. As buscas foram realizadas mediante os seguintes principais indexadores de pesquisa: Políticas Públicas; Avaliação de Políticas Públicas; Cooperativismo. Portanto, as fontes de informações são oficiais e públicas sendo basicamente documentais imediatas (Legislação, Projetos, Artigos e Periódicos científicos).

Para complementar, os documentos institucionais foram analisados, tendo em vista que esses documentos representam o sistema e a estrutura das instituições (VERGARA, 2005). Os documentos analisados compreendem desde relatos históricos sobre a gestão pública para o cooperativismo, que podem compreender jornais, quadros, murais, sites, relatórios, atas de reuniões, assim como qualquer outro documento informativo.

Ocorreram algumas delimitações para fins de exequibilidade, sendo incluídos no presente estudo: programas de gestão de políticas públicas por municípios do Brasil e do Tocantins, que contemplem o cooperativismo, que serviram de parâmetro, verificando-se 
o período de 2013 a 2017. Os modelos de programas analisados foram de municípios, que estão entre os que desenvolvem políticas públicas ou programas de iniciativa pública para o fomento do cooperativismo, com vias para o desenvolvimento das potencialidades locais, confrontando com a política existente no município de Gurupi-TO.

A partir dos modelos de políticas públicas voltados ao cooperativismo, existentes no Tocantins ou fora do Estado, se a política pública no município de Gurupi-TO se assemelhe e que, especificamente, seja voltada ao fomento do cooperativismo. Uma vez identificada a política pública municipal com este delineamento a mesma foi selecionada como objeto do estudo proposto, bem como os atores envolvidos na sua condução e os beneficiados pelas suas ações, os quais participaram após a necessária aprovação do projeto pelo Comitê de Ética em Pesquisa do Centro Universitário UnirG sob CAAE: 3357518.7.1001.5518, mediante aceite e assinatura do TCLE, para a realização de entrevistas individuais semiestruturadas.

O quantitativo de amostra para realização das entrevistas individuais seguiu a técnica da saturação teórica de Fontanella et al., (2008, p.17) a qual implica no "fechamento amostral por saturação teórica é operacionalmente definido como a suspensão de inclusão de novos participantes quando os dados obtidos passam a apresentar, na avaliação do pesquisador, certa redundância ou repetição, não sendo considerado relevante persistir na coleta de dados".

A percepção do ponto de saturação teórica é "quando os dados obtidos passam a apresentar, na avaliação do pesquisador uma certa redundância ou repetição, não sendo considerado relevante persistir na coleta de dados" (FONTANELLA; RICAS; TURATO, 2008, p.17). Desta forma, havendo repetição e nenhuma inovação na reflexão teórica na entrevista é sinal de que se alcançou a saturação.

A exemplo, foi formulado o quadro que demonstra a saturação teórica quanto à categoria das ações desenvolvidas pela política municipal de fomento ao cooperativismo na agricultura familiar em Gurupi-TO, conforme Quadro 1 a seguir.

Quadro 1- Ações da política municipal de fomento ao cooperativismo na agricultura familiar

\begin{tabular}{|c|c|c|c|c|c|c|c|c|c|c|c|c|c|c|}
\hline \multirow{2}{*}{ Ações } & \multicolumn{13}{|c|}{ Entrevistas } & \multirow{2}{*}{$\begin{array}{l}\text { Total de } \\
\text { Recorrênci } \\
\text { as }\end{array}$} \\
\hline & 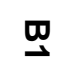 & 䍐 & 罵 & $\underset{\nabla}{\mathbb{D}}$ & 罚 & 四 & $\underset{v}{\mathscr{V}}$ & $\underset{\infty}{\mathbb{D}}$ & 眾 & ○田 & $-\underline{\boldsymbol{D}}$ & N 四 & $\omega \stackrel{\sigma}{\sigma}$ & \\
\hline $\begin{array}{l}\text { Preparação de } \\
\text { Solo } \\
\text { (maquinário) }\end{array}$ & $\mathrm{X}$ & $\mathrm{X}$ & & $\mathrm{X}$ & & $\mathrm{X}$ & & $\mathrm{X}$ & $\mathrm{X}$ & $\mathrm{X}$ & $\mathrm{X}$ & $\mathrm{X}$ & $\mathrm{X}$ & 10 \\
\hline Insumos & & $X$ & & & & & & & & & & & & 1 \\
\hline
\end{tabular}




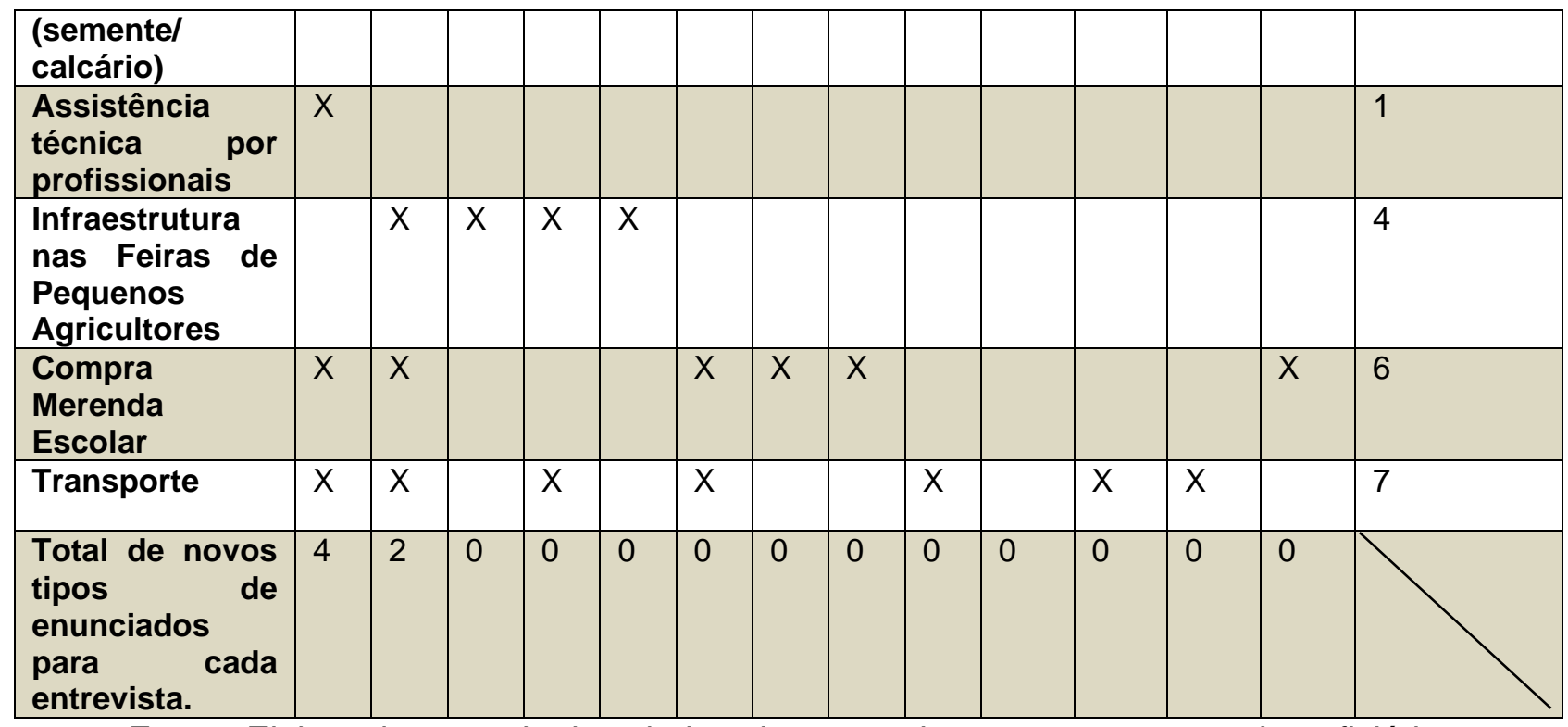

Fonte: Elaborado a partir dos dados das entrevistas com os atores-beneficiários com base em Fontanela et al., (2008).

No Quadro 1 percebe-se a saturação teórica da categoria "Ações Desenvolvidas", visto que os novos enunciados surgiram apenas nas duas primeiras entrevistas e nas demais houveram repetições dos enunciados e nenhuma inovação a esta categoria da entrevista semiestruturada aplicada.

O esforço de coleta de dados também foi realizado através de entrevistas individuais semiestruturadas com os gestores municipais (secretários e dirigentes), para o que foi necessária autorização tanto do gestor municipal quanto do responsável à sua época pela Secretaria Municipal de Produção, Meio Ambiente e Cooperativismo do município de Gurupi-TO. Obtida as autorizações, foi o momento de entrar em contato por telefone ou pessoalmente (considerando a disponibilidade do participante) com os ex-gestores que dirigiram a política pública municipal entre os anos de 2013-2017, sendo explicados os objetivos da pesquisa, e aos que aceitaram participar, foi agendada uma data para coleta do TCLE e realização da entrevista semiestruturada, as quais foram realizadas com 03 (três) ex-gestores e 01 (um) diretor, com duração média de 35 minutos, sendo identificados por G1, G2, G3 e G4 para a preservação da confidencialidade das identidades e das informações. As entrevistas foram gravadas, e posteriormente, transcritas, para então serem analisadas.

Os ex-gestores e dirigentes foram selecionados a partir dos decretos municipais de nomeação ao cargo de secretário municipal da Secretaria Municipal de Produção, Cooperativismo e Meio Ambiente a qual desenvolve ações em prol do cooperativismo municipal. Os beneficiados foram incluídos a partir dos seguintes critérios. 1ํ- ser 
associado a entidade representativa da agricultura familiar no município de Gurupi-TO; $2^{\circ}$ ser beneficiado pelas ações da política pública municipal há mais de 5 anos; $3^{\circ}$ - ter idade igual ou maior quee 18 anos; 4ํ- aceitar participar da pesquisa, assinando o TCLE. Foram excluídos da pesquisa os sujeitos que não se enquadraram nos critérios citados acima ou se ausentaram no dia designado para a entrevista ou desistiram no meio do processo de coleta de dados.

A partir da coleta dos dados, estes foram analisados mediante 0 Análise de Conteúdo, com a formulação de categorias as quais explicitam as constatações dos objetivos específicos traçados e encontrados conjuntamente com a descrição da política pública avaliada e as conclusões finais da pesquisa mediante a interpretação que se exige nesta técnica metodológica.

Torna-se importante ressaltar que para fins desta pesquisa, se adotou a sequência de passos, para a realização da análise de conteúdo preconizada por Bardin (2016), tendo em vista sua ampla utilização e popularidade nas pesquisas qualitativas Para tanto foram definidas as categorias de análise conforme foram surgindo à pesquisadora, ou seja, a grade de análise foi do tipo aberta.

Os resultados foram obtidos da análise de conteúdo da pesquisa documental e bibliográfica e das entrevistas realizadas com os atores sociais no total de 17 atores, sendo 04 ex-gestores e 13 beneficiários associados às organizações associativistas/cooperativistas no município de Gurupi-TO.

Agora, o estudo trará a importância das políticas públicas, em especial ao fomento do cooperativismo, como área de conhecimento suas delimitações conceituais, as tipologias, os ciclos e a avaliação das políticas públicas.

\section{DEFINIÇÃO E AVALIAÇÃO DAS POLITICAS PÚBLICAS}

O Brasil é um país historicamente marcado por sua diversidade natural e cultural. Da mesma forma, é notória a existência de desigualdades sociais e econômicas, como demonstram as estatísticas oficiais (PEREIRA, 2011).

Apesar de se tratar de fenômenos diversos, a pobreza, a desigualdade e a exclusão social estão intimamente inter-relacionadas, posto que a pobreza no Brasil não esteja determinada pela escassez de recursos e sim pela desigualdade na distribuição da renda e das oportunidades de inclusão econômica e social, conforme demonstra Barros (2004). 
Mais do que gerar trabalho e renda, o fomento ao cooperativismo que respeita seus princípios históricos, gera desenvolvimento sustentável, pois: reconstrói o tecido social; promove a geração e a distribuição de riquezas; o cuidado com a dimensão ambiental; rompe a subalternidade do trabalho frente ao capital; difunde a cultura da democracia, universalizando o direito de expressão, proposição e decisão no coração da atividade econômica, no interior das cooperativas, empresas e iniciativas de autogestão.

Nesta linha, Mance (2000) preceitua que além do crescimento do Produto Interno Bruto, tem-se a progressiva distribuição da riqueza produzida, o que amplia as possibilidades de consumo sustentável da sociedade, dinamizando o próprio desenvolvimento econômico.

Importante frisar as definições e fundamentos das políticas públicas, bem como as formas de consecução de seus objetivos.

Conforme Secchi (2015), a política, a partir do termo americano policy, refere-se ao posicionamento e orientações para a decisão e ação, fato que the confere uma dimensão mais prática e, assim, facilita compreender sua função no contexto social.

O autor menciona, ainda, que nas decisões políticas instituídas no âmbito do Estado há participação de diversos atores, dentre os quais se destacam os partidos políticos, agentes governamentais e diversos outros atores sociais, como representantes de movimentos sociais, de organizações não governamentais (ONGs) e da iniciativa privada.

Pode-se compreender as políticas públicas tomando por base duas correntes de pensamento: a norte-americana, centrada na ação de analisar as políticas públicas dentro uma lógica utilitarista, do ponto de vista de custos e resultados. E existe a outra vertente, a europeia que analisa as políticas públicas como um processo político e coletivo. Assim há a necessidade de discurso entre a ação do governo e a teoria de estado, em especial a que preza pelo coletivo, já que as políticas públicas têm como finalidade atender ao bem-estar da sociedade.

As políticas públicas devem ser direcionadas a solucionar demandas da coletividade, podendo incidir na vida privada dos cidadãos, sendo possível que as entidades privadas participem de sua formulação ou compartilhem sua implementação, e a possibilidade de o fazerem está amparada em decisões públicas, ou seja, decisões tomadas por agentes governamentais, emanadas do poder imperativo do Estado.

E, para efeito acadêmico, apresenta-se uma síntese teórico conceitual, no Quadro 2 adiante. 
DOI: 10.18605/2175-7275/cereus.v12n2p15-39
SCOTTA, K.C.P. CANÇADO, A.C

Análise da política pública municipal de fomento ao cooperativismo no Município de Gurupi-TO.

Quadro 2- Quadro Teórico-Conceitual de 'Políticas Públicas

\begin{tabular}{|c|c|}
\hline Autor & Definição \\
\hline Laswell (1950) & $\begin{array}{l}\text { "as políticas públicas eram, de fato, a concretização do governo em ação, quase um } \\
\text { ato de governing, conjugado com o tempo verbal no gerúndio), seus estudos } \\
\text { deveriam também assumir a intencionalidade de tais ações adotando uma } \\
\text { perspectiva prescritiva, de forma que as decisões e análises sobre política pública } \\
\text { convirja à responder às seguintes indagações: quem ganha o quê, por que e que } \\
\text { diferença faz." }\end{array}$ \\
\hline Dye (1972) & $\begin{array}{l}\text { descreve a política pública como "tudo o que um governo decide fazer ou deixar de } \\
\text { fazer". }\end{array}$ \\
\hline Jenkins (1978) & $\begin{array}{l}\text { "conjunto de decisões inter-relacionadas tomadas por um ator individual ou por um } \\
\text { conjunto de atores, referentes à seleção de objetivos e de meios para atingi-los em } \\
\text { uma situação em que atores possuem condições de alcançar tais objetivos". }\end{array}$ \\
\hline Souza (2006) & $\begin{array}{l}\text { "Campo do conhecimento que busca, ao mesmo tempo, "colocar o governo em ação" } \\
\text { e/ou analisar essa ação (variável independente) e, quando necessário propor } \\
\text { mudanças no rumo ou curso dessas ações (variável dependente)". }\end{array}$ \\
\hline Autor & Definição \\
\hline Souza (2007) & $\begin{array}{l}\text { "Não existe uma única, nem melhor, definição sobre o que seja política pública. Mead } \\
\text { (1995) a define como um campo dentro do estudo da política que analisa o governo à } \\
\text { luz de grandes questões públicas e Lynn (1980), como um conjunto de ações do } \\
\text { governo que irão produzir efeitos específicos. Peters (1986) segue o mesmo veio: } \\
\text { política pública é a soma das atividades dos governos, que agem diretamente ou } \\
\text { através de delegação, e que influenciam a vida dos cidadãos. Dye (1984) sintetiza a } \\
\text { definição de política pública como 'o que o governo escolhe fazer ou não fazer'. A } \\
\text { definição mais conhecida continua sendo a de Laswell, ou seja, decisões e análises } \\
\text { sobre política pública implicam responder às seguintes questões: quem ganha o quê, } \\
\text { por que e que diferença faz". (CONTINUA) }\end{array}$ \\
\hline Rua (2013) & $\begin{array}{l}\text { (...) políticas públicas (policy) são uma das resultantes da atividade política (politics): } \\
\text { compreendem o conjunto das decisões e ações relativas à alocação imperativa de } \\
\text { valores envolvendo bens públicos. "É importante desenvolver a compreensão de que } \\
\text { as políticas públicas são resultantes da atividade política e que esta consiste na } \\
\text { resolução pacífica de conflitos, processo essencial à preservação da vida em } \\
\text { sociedade". }\end{array}$ \\
\hline Amabile (2012) & $\begin{array}{l}\text { "são decisões que envolvem questões de ordem pública com abrangência ampla e } \\
\text { que visam à satisfação do interesse de uma coletividade. Podem também ser } \\
\text { compreendidas como estratégias de atuação pública, estruturadas por meio de um } \\
\text { processo decisório composto de variáveis complexas que impactam na realidade. } \\
\text { São de responsabilidade da autoridade formal legalmente constituída para promovê- } \\
\text { las, mas tal encargo vem sendo cada vez mais compartilhado com a sociedade civil } \\
\text { por meio do desenvolvimento de variados mecanismos de participação no processo } \\
\text { decisório". }\end{array}$ \\
\hline $\begin{array}{l}\text { Howlett et al. } \\
\text { (2013) }\end{array}$ & $\begin{array}{l}\text { "a policy-making trata fundamentalmente de atores cercados por restrições que } \\
\text { tenham que compatibilizar objetivos políticos (policy goals) com meios políticos } \\
\text { (policy means) em um processo que pode ser caracterizado como "resolução } \\
\text { aplicada de problemas"no processo decisório". }\end{array}$ \\
\hline Secchi (2015) & $\begin{array}{l}\text { "uma diretriz elaborada para enfrentar um problema público [...], uma política é uma } \\
\text { orientação à atividade ou à passividade de alguém; as atividades ou passividades } \\
\text { decorrentes dessa orientação também fazem parte da política pública". }\end{array}$ \\
\hline
\end{tabular}

Fonte: Elaborado pela autora (2018).

A partir das definições sobre 'política pública' alhures delineadas percebe-se que, até então, o governo atua como ator principal para consecução das finalidades de uma sociedade justa e igualitária e para tanto a política pública desempenha papel central na vida das pessoas, por ser um fator primordial para contribuir com o bem-estar da sociedade. 
Portanto, parte-se do pressuposto que as políticas públicas são formuladas para propiciar melhores condições de bem-estar à população e, a sociedade, enquanto fim da política pública, possui papel substancial em seu processo de definição, elaboração, implementação e avaliação.

Nesse aspecto, o Brasil se destaca como país que se beneficiou, na última década, por adotar políticas de promoção do crescimento com equidade, mesmo que ainda necessite avançar para aprimorar o alcance dessas políticas. Portanto, para que a sociedade supra suas necessidades, o governo precisa ser eficaz na produção das políticas públicas, realizando-as de forma satisfatória, pois as boas políticas públicas são construídas de forma consciente, ou seja, os governos necessitam de processos eficientes para alocar e equilibrar as demandas de forma a solucionar o núcleo dos problemas.

Considerando essa complexa relação entre governo e sociedade, o processo político está repleto de irracionalidades, de inconsistências e de razões para a falta de coordenação. Essas deficiências derivam, muitas vezes, de fonte de políticas pouco resistentes, visto que, se tanto as pessoas que participam quanto as que não participam dos governos deixam de ter familiaridade com a natureza e o funcionamento do processo político, elas provavelmente não consigam imaginar estratégias de sucesso para influenciar seu rumo e assegurar que elas produzam resultados eficazes (HOWLETT; RAMESH; PERL, 2013).

Antes, cabe aqui destacar que, como visto, o conceito de política pública é transversal a diversas áreas ou setores de intervenção pública se ajustando de acordo com o problema público identificado, estabelecendo uma relação causal. Em outras palavras, dependendo do tipo de política pública que está em jogo, a estruturação dos conflitos, das coalizões e o equilíbrio de poder se modificam, determinando a dinâmica política e quiçá o processo político.

Portanto, para os fins desejados deste estudo, o conceito de Secchi (2015) é o mais indicado, pois entende que as políticas públicas devem ser desenvolvidas para o enfrentamento de um problema público com a finalidade de orientar as atividades para resolução do problema ou mesmo em casos de omissão ou passividade, as políticas públicas também são capazes de suprir tais carências, de ordem econômica, social e cultural.

Dentre os objetivos deste trabalho está a missão de avaliar a política pública municipal para o cooperativismo em Gurupi-TO com base na percepção dos gestores 
públicos, dirigentes e beneficiários em relação ao desempenho qualitativo com o intuito de conhecer melhor o estado da política e o nível de redução do problema público que a motivou.

A avaliação de políticas públicas cumpre papel fundamental no aprimoramento destas, para isso, é "fundamental que o uso destas metodologias possibilite que sejam feitas inferências descritivas válidas, confiáveis e isentas, identificando as razões que são responsáveis pelo impacto do programa" (BARROS, 2004, p.2).

Para a consecução da fase de avaliação de política pública impõe-se a definição de critérios e indicadores sobre as alternativas escolhidas e especificadas da política pública (SECCHI, 2015). Os critérios e indicadores são os elementos sobre os quais os potenciais resultados das alternativas de políticas públicas serão avaliados e ranqueados. Nesse sentido, critérios e indicadores não avaliam as alternativas em si, mas, sim, os futuros cenários que são derivados da aplicação da alternativa (THISSEN;WALKER, 2013).

$\mathrm{Na}$ seção a seguir serão apresentadas as nuances do cooperativismo nacional, regional e local.

\section{COOPERATIVISMO NO BRASIL, NO TOCANTINS E EM GURUPI-TO}

A primeira política nacional de cooperativismo veio através da intervenção estatal com a edição do Estatuto da Terra (Lei $n$. ․ 4.504/1964) concedendo ao Instituto Nacional de Colonização e Reforma Agrária (INCRA) as funções de normatizar, registrar e fiscalizar o funcionamento das cooperativas e das associações rurais e posteriormente com 0 Decreto-Lei n. 60.957 de 1967 criou-se o Conselho Nacional de Cooperativismo (CNC) (SILVA; PETARLY, 2015).

Em 1969 foi criada a Organização das Cooperativas Brasileiras (OCB) com a missão de representar uma liderança cooperativista uníssona promovendo a união de todo o movimento e ainda com a missão de elaborar uma lei própria para o sistema cooperativista e em 16 de dezembro de 1971 foi aprovada a Lei $n .05 .764$ a qual traz 0 regime jurídico de regulação das sociedades cooperativas (OCB, 2018; SILVA: PETARLY, 2015).

Com a promulgação da Lei do Cooperativismo (Lei n.5.764/1971), inaugurou a era de renovação e fixação da doutrina cooperativista, baseada na diminuição da intervenção estatal. O marco regulatório do cooperativismo trata basicamente sobre a abertura, manutenção, principalmente das cooperativas agropecuárias, cooperativas de crédito e 
cooperativas de consumo, contribuindo com a reversão do processo de encolhimento do sistema cooperativo, ou seja, o cooperativismo voltou a prosperar (LEOPOLDINO, 2011).

O ano de 1988 - um marco na política nacional - contou com grandes conquistas do cooperativismo junto à Assembleia Nacional Constituinte, sendo a principal delas a suspensão das limitações da Lei n 5.764, de 1971. A Constituição de 1988 inaugura a era da autogestão ${ }^{1}$ cooperativista, ao proibir a interferência do Estado nas associações desse setor (OCB, 2018).

Outro marco normativo para o cooperativismo brasileiro é o atual Código Civil Brasileiro (Lei n. 10.406 de 10 de janeiro de 2002) se incumbindo em um capítulo específico sobre as sociedades cooperativas (artigo 1.093 a 1.096), porém, limitou-se a desenvolver os princípios a serem aplicados à espécie societária, não trazendo à baila grandes novidades sobre o assunto (LEOPOLDINO, 2011).

Sem nenhuma dúvida, a cooperativa é uma das formas avançadas de organização da sociedade civil, proporcionando o desenvolvimento socioeconômico aos associados e à comunidade, resgatando a cidadania por meio da participação, do exercício da democracia, da liberdade e autonomia. Portanto, a consolidação do sistema cooperativista no Brasil tem papel significativo no desenvolvimento da sociedade, promovendo acesso ao crédito, saúde, educação, moradia e ao mercado de trabalho, com responsabilidades sociais e ambientais (OCB, 2018).

Números e informações demonstram a importância das cooperativas. De acordo com dados produzidos pela Sescoop/RS em 2017², o cooperativismo gera significativos resultados no país e no mundo, sendo a principal fonte de renda de mais de 1 bilhão de pessoas.

Se as cooperativas existentes no mundo fossem um país, elas seriam a 6 maior economia do mundo, com um PIB de US\$ 2,53 bilhões. No mundo, 1 em cada 7 pessoas está associada a uma cooperativa.

No Brasil, 51,6 milhões de pessoas são beneficiadas direta ou indiretamente pelo cooperativismo. Assim são os números do cooperativismo no Brasil, segundo a OCB: Em 564 municípios brasileiros, as cooperativas de crédito são as únicas instituições

\footnotetext{
1 No contexto da Constituição Federal de 1988, autogestão é entendida como a gestão das cooperativas por seus cooperados sem interferência do Estado. Todavia, os conceitos de autogestão variam de acordo com as posições políticas ou sociais.

2 Dados publicados pela Revista Expressão do Cooperativismo Gaúcho 2017, produzida pelo Sistema OcergsSescoop/RS lançada em junho de 2017, com dados atualizados no site <disponível em: http://geracaocooperacao.com.br/numero-do-cooperativismo-no-brasil-e-no-mundo/> Acesso em 10 de fevereiro de 2018.
} 
financeiras locais; 807 municípios são atendidos por cooperativas de eletrificação no país; 428 milhões de toneladas de cargas são transportadas anualmente por cooperativas; 48\% de toda produção agrícola brasileira passa de alguma maneira por uma cooperativa agropecuária; As cooperativas são responsáveis por mais de $70 \%$ da produção de trigo, mais de $40 \%$ da de soja, $40 \%$ da de leite, $38 \%$ de algodão, $21 \%$ do café e $16 \%$ do milho brasileiros; 38\% dos brasileiros com assistência médica são atendidos por cooperativa de saúde; 372 mil empregos brasileiros são gerados pelas cooperativas; US $\$ 5,137$ bilhões é o volume de recursos movimentados pelas exportações realizadas por 240 cooperativas brasileiras a 147 países; São 6,6 mil cooperativas no Brasil.

Portanto, fica evidente que o cooperativismo contribui substancialmente para o desenvolvimento econômico e humano no Brasil.

O cooperativismo no Tocantins coincide com o cooperativismo do Estado de Goiás, porém conquista os anais da história com a criação do Estado em 1988. Desde o norte goiano já existiam algumas cooperativas em operação, que a partir da criação da Organização das Cooperativas do Estado do Tocantins, passaram a compor a esta organização.

Desde a criação do Estado do Tocantins (1988), apenas em 2012, foi criada a Lei no 2.594, de 11 de junho de 2012, que instituiu a Política Estadual de Apoio ao Cooperativismo (PEAC), com a finalidade de promover o desenvolvimento social, econômico e cultural do setor cooperativo em nível estadual. A lei também estimula pesquisadores, parceiros e empreendedores sociais a elaborarem estudos, pesquisas e publicação de material didático de apoio, de modo a despertar a produção intelectual e acadêmica em torno da temática (TOCANTINS, 2013).

Para as cooperativas com aptidão agrícola de destaque, a exemplo da Cooperativa Agropecuária Tocantinense (COAPA) que se consolida como referência no Estado tanto em termos de produtividade, na organização dos produtores e qualificação da gestão. $E$ ainda, no que se refere à agricultura familiar, a Cooperativa dos Agricultores Familiares do Bico do Papagaio (COAF-Bico) se consolida na intermediação da comercialização dos produtos agrícolas.

Desta forma, as cooperativas se estabelecem como um espaço democrático favorecendo sua responsabilidade pelo desenvolvimento.

Ao promover o desenvolvimento, as cooperativas são veículos de mobilização de recursos nas comunidades onde estão localizadas haja vista o empenho na promoção de 
ações que fomentam a produção de bens e serviços e consequentemente beneficia a circulação de recursos na própria comunidade.

E dentre os aspectos do desenvolvimento local, a atividade cooperativa também promove a geração de emprego e renda, pois através do sistema de cooperativa 0 cidadão tem condições de se inserir na compra, venda, uso e fornecimento de bens e serviços se beneficiando de melhores condições de trabalho e renda, gerando oportunidades e qualidade de vida no meio.

Segundo dados da SESCOOP sobre o panorama do cooperativismo no Estado do Tocantins o ano de 2015 fechou com um total de 45 cooperativas distribuídas nos ramos elencados no Quadro 3, a seguir:

Quadro 1 - Ramos de cooperativas no Tocantins

\begin{tabular}{|l|c|}
\hline RAMOS DE COOPERATIVAS & ANO DE 2015 \\
\hline Agropecuário & 14 \\
\hline Consumo & 0 \\
\hline Crédito & 03 \\
\hline Educacional & 04 \\
\hline Especial & 0 \\
\hline Habitacional & 0 \\
\hline Infraestrutura & 0 \\
\hline Mineral & 03 \\
\hline Produção & 01 \\
\hline Saúde & 07 \\
\hline Trabalho & 06 \\
\hline Transporte & 07 \\
\hline Turismo e Lazer & 0 \\
\hline TOTAL & $\mathbf{4 5}$ \\
\hline
\end{tabular}

Fonte: SESCOOP $(2018, \mathrm{~s} / \mathrm{p})$.

Em âmbito local, no município de Gurupi-TO, a que este trabalho se dirige, o cooperativismo é idealizado como um pilar na gestão pública, a exemplo da edição da Lei Municipal n. 1.188 de 30 de junho de 1997, que trouxe a necessidade do fortalecimento do cooperativismo, como articulação de medidas de melhoria da população do meio rural. A partir de então o cooperativismo é a base de sustentação para a implementação da política pública municipal desenvolvimentista.

No município as potencialidades locais podem ser avaliadas a fim de diagnosticar as condições para o desenvolvimento econômico, social e cultural da comunidade envolvida. Diante disto, o cooperativismo pode contribuir para a melhoria da qualidade de vida daqueles que estejam em condições econômicas e sociais vulneráveis.

No caso de Gurupi-TO o potencial local está ligado às atividades agropecuárias, devido a potencialidade promissora da região e sua consolidação no mercado, como polo 
regional do sul tocantinense.

Segundo dados do sistema OCB/Sescoop em Gurupi existem 08 (oito) cooperativas ativas, conforme listadas no Quadro 4.

Quadro 2 - Cooperativas ativas em Gurupi - TO.

\begin{tabular}{|c|c|}
\hline N. & COOPERATIVAS \\
\hline 1 & IMED GURUPI COOPERATIVA DE TRABALHO MÉDICO (Continua) \\
\hline N. & OOPERATIVAS \\
\hline 2 & COOPERATIVA DOS PRODUTORES DE CARNE E DERIVADOS DE GURUPI - COOPERFRIGU \\
\hline 3 & $\begin{array}{llllllll}\text { COOPERATIVA DOS PRODUTORES } & \text { AGROPECUÁRIOS } & \text { DO } & \text { SUL } & \text { DO } & \text { TOCANTINS - } \\
\text { COOPERSUL }\end{array}$ \\
\hline 4 & COOPERATIVA DE USUARIOS DE ASSISTENCIA MEDICA USIMED GURUPI \\
\hline 5 & COOPERATIVA REGIONAL DOS PRODUTORES DA AGRICULTURA FAMILIAR - COORPAF \\
\hline 6 & 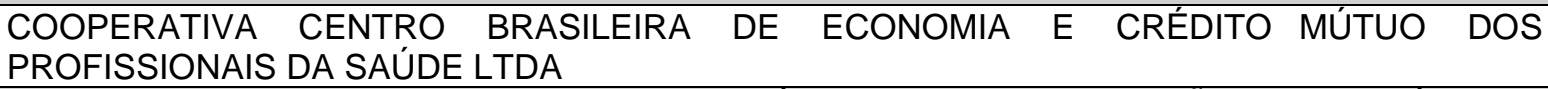 \\
\hline 7 & $\begin{array}{l}\text { SICOOB CREDIPAR - COOPERATIVA DE CRÉDITO E LIVRE ADMISSÃO DE PARAÍSO DO } \\
\text { TOCANTINS E REGIÃO LTDA }\end{array}$ \\
\hline 8 & $\begin{array}{l}\text { SICREDI - COOPERATIVA DE CREDITO RURAL E DOS SERVIDORES PÚBLICOS ESTADUAIS } \\
\text { DO ESTADO DO TOCANTINS }\end{array}$ \\
\hline
\end{tabular}

Fonte: OCB/Sescoop (2018, s/p).

Durante a realização deste trabalho foi percebido o grau de relevância da atuação destas cooperativas para o desenvolvimento local, considerando seu impacto social e econômico.

\section{RESULTADOS E DISCUSSÃO}

A partir da metodologia empregada, passou-se a analisar a política pública municipal de fomento ao cooperativismo entre os anos de 2013 a 2017 com o propósito de avaliar a Política Pública na visão dos atores.

A avaliação é a fase do ciclo de políticas públicas em que o processo de implantação e o desempenho da política pública são examinados com o intuito de conhecer melhor o estado da política e o nível de redução do problema que a gerou.

O presente trabalho privilegiou uma avaliação com conotação política, segundo (SECCHI, 2015), considerando os aspectos como: a legitimidade do processo de elaboração das ações, a percepção dos beneficiários da política pública com a indicação dos benefícios e impactos e a participação dos atores na condução da política pública de fomento ao cooperativismo.

No que se refere à legitimidade do processo de elaboração das ações, G3 e G4 apontaram a existência e relevância do Conselho de Desenvolvimento Rural Sustentável no qual são debatidos os problemas existentes enfrentados tanto pela gestão quanto pelos produtores/beneficiários da política existente sendo confirmado pelo beneficiário B2, note. 
(...) o Conselho de Desenvolvimento Rural Sustentável que foi criado também já nesta gestão justamente a gente por exemplo analisa as ações desenvolvidas e as que não deu muito certo nesse ano o que que a gente pode estar fazendo para melhorar (...); Ouvindo eles, as Associações são representadas no Conselho e tem participado das reuniões, a gente faz um planejamento com a participação deles, não é um planejamento que sai apenas da Diretoria (G4).

Tem as entidades relevantes que participam das ações desenvolvidas como o Conselho de Desenvolvimento Rural (G3).

(...) a gente tem um Conselho de Desenvolvimento Rural Sustentável que eu acho que é o que cuida mais dessas ações, determina (B2).

Os depoimentos demonstram a existência de um canal legítimo e organizado de forma paritária para as deliberações relativas á política pública existente, permitindo a influência dos cidadãos nas decisões tomadas.

Sobre a percepção dos benefícios e impactos gerados pela política pública existente de fomento ao cooperativismo, os benefícios mencionados são: melhoria do trabalho e da renda por meio de programas governamentais de compra de produtos, a melhoria na produtividade por meio das assistências técnicas e apoio com infraestrutura com a melhoria das estradas, oferta de transporte de produtos para venda e dos insumos.

Tais benefícios e impactos são assim relatados pelos beneficiários

A gente tinha bastante incentivo da prefeitura tanto na apicultura quanto na agricultura (...); a prefeitura deu cursos de apicultura, deu um pouco de material, deu as caixas, macacão, foi 4 caixas para cada produtor, foi aí que começou a produção de mel na região de Gurupi (...); Olha eles [a gestão] sempre dão assistência técnica pra gente, o técnico vai lá pra ajudar no plantio, no preparo da terra (B1).

Tem o programa de desenvolvimento rural através da agricultura familiar para dar assistência pra nós no caso do preparo do solo. Nós temos a condução [transporte] pra pegar nossos produtos aqui porque a gente vende pra prefeitura pra merenda escolar (B2).

Temos de benefício a feira do produtor que é muito boa pra vender (B3).

Os benefícios que nós temos é que com a feira aumentou a renda do produtor, melhorou bastante (B4).

Nós temos cursos para melhorar a produção e esta feira que é boa demais (B5).

Ela [a gestão] arruma as estradas quando precisa, manda as máquinas pra gradear, jogar calcário, isso é muito bom pra nós (B6).

As feiras "veio" na hora certa pra gente conseguir vender os produtos la da roça (B7).

Aumenta a renda porque a gente passou a vender mais nas feiras e pra merenda escolar (B8).

Eles levam tratores pra ajudar no preparo da terra e nas estradas, manda carro pra nós despachar as mercadorias pras escolas e nas feiras (B9).

Ela [gestão] dá os tratores para gradear as terras, dá muito apoio e benefício pra nós (B10).

Eles [gestão] dão o trator, o ônibus pra buscar e levar nós, faz ponte e arruma as estradas (B11).

Temos trator e ônibus para ajudar nós (B12).

A compra direta melhorou muito nossa renda, os tratores na época do plantio são muito bons pra ajudar na plantação (B13).

Os ex-gestores também relatam sobre os benefícios da política existente: 
(...) hoje o resultado que nós temos ai é uma feira organizada que acontece 3 vezes por semana (G1).

(...) as políticas públicas, por exemplo, do compra direta, com doação simultânea, das compras governamentais pela própria secretaria de educação aonde pelo menos $30 \%$ da merenda escolar ela tem que vim da origem agricultura familiar então essas políticas públicas elas existem aqui (...) (G2).

(...) a patrulha mecanizada foi uma importante aquisição para fomentar a produção local, a gestão oferta o operador da maquina, o combustível tudo para facilitar a vida do pequeno produtor (G3).

(...)os produtores hoje eles recebem apoio desde o preparo do solo, orientações, cursos, de apicultura, agricultura orgânica e vários outros custos até mesmo de NCR (negócio certo rural), aprender como se planeja sua produção, até a hora de comercializar, eles tem um apoio logístico, foram criadas três feiras exclusivas para eles [beneficiário] (G4).

Os depoimentos acima evidenciam que a política existente gera benefícios e por consequência impacta positivamente a vida destes beneficiários, ou melhor, proporciona melhor qualidade de vida. Por isso, é perceptível o avanço em relação aos efeitos da política pública analisada como alternativa na resolução do problema social relacionado à oferta de trabalho e renda desta parcela da população, qual seja, da agricultura familiar.

\section{Quanto à participação dos atores na condução da política a maioria manifestou}

exercer com liberdade sua participação, falando, ouvindo, dando sugestões nas deliberações coletivas, a seguir os depoimentos:

\footnotetext{
Muitas vezes eles [gestores] já levam o projeto pronto, apresenta e orienta a gente participar porque é bom pra nós. Muitas vezes marcam reunião, a associação convida o pessoal e muitas vezes eles [beneficiários] não vão (...); A gestão sempre que tem alguma coisa a fazer eles convidam e participam e a maioria dos produtores só ouve (B1).

Sempre que está em reunião com a gente, sempre participo (...) (B2).

Eu sempre falo e às vezes me ignoram porque não venho nas reuniões pra ficar calado, porque se eu não falar não vão saber o que estamos sentindo ou precisando (B3).

De vez em quando tem reunião sim, a gente participa (...) (B4).

Já participei de algumas reuniões, mas não sou de falar muito, só de ouvir (B5).

Sempre que tem reunião é muito boa e proveitosa (B6).

A prefeitura faz reuniões frequentes, teve uma mês passado e eu tenho participado (B7).

Eles sempre fazem reuniões com a gente, tem umas que fui e outras não (B8).
}

Para este critério, de acordo com Tenório (2010, p.6) é definida como: "dotados de informação e com acesso livre aos canais de deliberação, qualquer individuo (cidadão) ou organização é passível de influenciar as decisões tomadas via processo deliberativo".

Portanto, as falas acima mostram a importância da participação das pessoas na busca de seus direitos, quanto mais a pessoa participa, mais ela busca conhecimento dos seus direitos e deveres, mas sem atuar, fica difícil de melhorar a qualidade de vida em todos os setores, seja no trabalho, na educação ou saúde. 
DOI: 10.18605/2175-7275/cereus.v12n2p15-39
SCOTTA, K.C.P. CANÇADO, A.C

Análise da política pública municipal de fomento ao cooperativismo no Município de Gurupi-TO.

Nas entrevistas semiestruturadas realizadas com ambos os atores, foi-lhes perguntado: "Em uma escala de 1 a 5, sendo: 1- ruim; 2- regular; 3-bom; 4- muito bom e 5-excelente, qual seria sua avaliação da política existente?" sendo respondido conforme o quadro 5 abaixo.

Quadro 5- Avaliação dos atores sobre a política pública existente

\begin{tabular}{|c|c|c|c|c|c|}
\hline ATORES & 1-RUIM & 2- REGULAR & 3-BOM & $\begin{array}{c}\text { 4-MUITO } \\
\text { BOM }\end{array}$ & 5-EXCELENTE \\
\hline G1 & & $\mathrm{X}$ & & & \\
\hline G2 & & $X$ & & & \\
\hline G3 & & $\mathrm{X}$ & & & \\
\hline G4 & & & & $X$ & \\
\hline B1 & & & $X$ & & \\
\hline B2 & & & $\mathrm{X}$ & & \\
\hline B3 & & & $\mathrm{X}$ & & \\
\hline ATORES & 1-RUIM & 2- REGULAR & 3-BOM & $\begin{array}{c}\text { 4-MUITO } \\
\text { BOM }\end{array}$ & 5-EXCELENTE \\
\hline B4 & & & $\mathrm{X}$ & & \\
\hline B5 & & $X$ & & & \\
\hline B6 & & $\mathrm{X}$ & & & \\
\hline B7 & & & & & $\mathrm{X}$ \\
\hline B8 & & & & $X$ & \\
\hline B9 & $X$ & & & & \\
\hline B10 & & & & $\mathrm{X}$ & \\
\hline B11 & & & & & $X$ \\
\hline B12 & & $X$ & & & \\
\hline B13 & & $x$ & & & \\
\hline & 01 & 07 & 04 & 03 & 02 \\
\hline TOTAL & $5,89 \%$ & $41,18 \%$ & $23,53 \%$ & $17,64 \%$ & $11,76 \%$ \\
\hline
\end{tabular}

Fonte: Dados da pesquisa, 2018.

O resultado da avaliação acima conclui que o público entrevistado dividiu-se no resultado final, sendo que 52,93\% considerou satisfatória (bom a excelente) a política de fomento ao cooperativismo de Gurupi-TO e 41,18\% a considerou regular (ruim a regular), ressalvando aspectos da política a serem aperfeiçoados.

Acho que deveria melhorar a comunicação entre os gestores e os produtores, porque muitas reuniões são marcadas e o pessoal da prefeitura não vai (B1).

Tem que ter um melhor empenho na implantação do CEASA para nós, seria um incentivo pra produzir e vender mais (B3).

A gestão poderia acompanhar as associações mais de perto e ver como elas funcionam e precisam de ajuda para melhorar (B5).

Melhorar as estradas (B6/B7/B8/B12 e B13).

Na percepção dos ex-gestores:

A política precisa ter continuidade, se a cada gestão você tem uma interrupção você tem uma volta ao passado, então a motivação, tudo que você faz tem que ter uma sequência, persistência, tem que perseverar porque se você sofrer 
interrupção você tem retrocesso (G1).

(...) a cultura da cooperação ela tem que ser excelente pra Gurupi e região, agora hoje ela não se faz excelente então nós temos uma oportunidade de preconizar uma cultura diferente e ai eu acredito a própria secretaria, o trabalho realizado vai oportunizar isso a caminhos pra gente se torna excelente que hoje eu vejo como insipiente que as pessoas não falam, é acanhado, as pessoas na verdade quando fala de cultura de cooperativismo as pessoas, elas maculam aquela imagem antiga da cooperativa que não deu certo na nossa região, nós precisamos sim, de ter uma política pública que instrumentaliza, agora esse é um grande desafio porque nem todo mundo quer o sistema produtivo organizado e estruturado (G2)

(...) os gestores não tem afinidade em trabalhar com a parte do cooperativismo. Aqui não tem diretor de cooperativismo. Então como fomentar isso se você não tem pessoas em condição de trabalhar. É assim se colocar as pessoas no lugar certo elas vão desenvolver as coisas certas. Então você vai colocar pessoas erradas elas não vão desenvolver. Os secretários aqui são políticos, que é a coisa mais ridícula que eu já vi, esse deveria ser um cargo técnico (G3).

Temos muito que ainda melhorar nessa questão do cooperativismo e fazer com que a população e as classes produtivas possam entender a importância do cooperativismo para o desenvolvimento social e econômico da região. A nossa vantagem no momento é que a gente tem um gestor com essa visão voltada para incentivar o cooperativismo (G4).

Dentre os aspectos mencionados pelos entrevistados para o aprimoramento da política pública existente temos: a comunicação entre a gestão e os beneficiários, infraestrutura, monitoramento das associações beneficiadas, continuidade das ações na sucessão entre as gestões, educação e cultura para o aperfeiçoamento do cooperativismo local e nomeação de gestores e servidores técnicos e capacitados para desenvolver o cooperativismo local.

Quadro 6- Síntese da Avaliação da Política Pública na visão dos atores

\begin{tabular}{|c|c|}
\hline Critérios & Descrição \\
\hline $\begin{array}{l}\text { Legitimidade do processo de elaboração das } \\
\text { ações }\end{array}$ & $\begin{array}{l}\text { O funcionamento do Conselho Municipal de } \\
\text { Desenvolvimento Rural, sua formação paritária com a } \\
\text { sociedade repercute na legitimação do processo } \\
\text { deliberativo da política pública existente. }\end{array}$ \\
\hline Percepção dos benefícios e impactos gerados & $\begin{array}{l}\text { Foram mencionados pelos entrevistados alguns } \\
\text { benefícios dentre os quais destacam-se: investimento } \\
\text { na infraestrutura das estradas, assistência técnica para } \\
\text { os produtores, patrulha mecanizada para preparo do } \\
\text { solo, oferta de transporte público gratuito dos } \\
\text { produtores e produção; compra direta e para merenda } \\
\text { escolar da produção, gerando impacto na melhoria do } \\
\text { trabalho e aumento na renda dos produtores. }\end{array}$ \\
\hline Participação dos atores na condução da política & $\begin{array}{l}\text { Manifestaram exercer com liberdade sua participação, } \\
\text { falando, ouvindo, dando sugestões nas deliberações } \\
\text { coletivas, com a possibilidade de acatamento pela } \\
\text { gestão. }\end{array}$ \\
\hline
\end{tabular}

Fonte: Dados da pesquisa, 2018.

Assim como a política existente é direcionada ao desenvolvimento da produção local proveniente da agricultura familiar o público beneficiário está concentrado na formação das associações locais que possuem representatividade perante o Conselho Municipal de 
Desenvolvimento Rural bem como promove a intermediação das ações da gestão pública municipal para os associados proporcionando impactos positivos na geração de trabalho e aumento da renda familiar.

Portanto, a política pública municipal para o cooperativismo em Gurupi-TO baseando-se na percepção dos gestores públicos, dirigentes e beneficiários pode ser avaliada como satisfatória ${ }^{3}$ visto que sua idealização e condução pauta-se na legitimidade das ações desenvolvidas as quais são decididas mediante deliberação coletiva em Conselho formado para tal finalidade, sendo este esfera constituída de forma paritária entre atores públicos, beneficiários e sociedade civil organizada e a participação dos beneficiários.

Sobre a condução da política pública foi mencionado pelos beneficiários que a participação se efetivou de forma livre e sem coações, apesar da ressalva de que nem todas as manifestações e solicitações não são acatadas pela gestão municipal, visto que cabe a esta decidir, pautada na discricionariedade, quais ações são realmente necessárias ao menor custo.

Quanto aos benefícios e os impactos promovidos pela política analisada, consistem na maioria das opiniões dos beneficiários, em ações de infraestrutura que viabilizam a produção local provenientes da agricultura familiar gerando impactos positivos e relevantes nas condições de trabalho e renda e por consequência na melhoria da qualidade de vida dos beneficiários, conforme demonstra a literatura recorrente.

Tem-se como desafios a serem enfrentados pela gestão da política pública: a consolidação da efetividade da política pública de fomento ao cooperativismo por meio de ações contínuas de educação e cultura cooperativista, manutenção de uma gestão pública dirigida por atores capacitados e comprometimento governamental e institucional para a consolidação de cooperativas rurais, em especial que abrange atividades de agricultura familiar.

Quanto ao aprimoramento dos canais de comunicação entre a gestão e os beneficiários, a divulgação das ações e deliberações bem como a participação efetiva dos beneficiários na gestão da política pública são temas de deliberação coletiva e que nas sessões ambos os atores podem manifestar e em consenso coletivo analisar o que melhor atende as necessidades.

Portanto, entende-se que a consolidação da gestão da política pública de fomento 
ao cooperativismo através dos indicadores ora analisados pode vir a ser efetivada através da edição de lei municipal que regulamente o cooperativismo e as ações desenvolvidas pela gestão municipal como instrumento estratégico na promoção do fortalecimento econômico, social e político dos beneficiários da política municipal de fomento ao cooperativismo.

\section{CONSIDERAÇÕES FINAIS}

Como objetivo central deste trabalho foi avaliar a política pública municipal de fomento ao cooperativismo nos anos de 2013 a 2017 em Gurupi-TO e como objetivos específicos: 1) Avaliar a política pública municipal para o cooperativismo em Gurupi-TO com base na percepção dos gestores públicos, dirigentes e beneficiários em relação ao desempenho qualitativo da política pública municipal e 2) Identificar os desafios e propor diretrizes para a consolidação da gestão da política pública de fomento ao cooperativismo no município de Gurupi-TO.

Com a interpretação e inferência a partir das entrevistas semiestruturadas foi possível avaliar o desempenho qualitativo da política pública municipal através de indicadores de conotação política (SECCHI, 2015) indicando que a política existente de fomento ao cooperativismo é satisfatória, contudo necessita aperfeiçoar os canais de comunicação entre a gestão e os beneficiários, infraestrutura e monitoramento das associações/cooperativas beneficiadas o que pode acontecer por meio da consolidação de um instrumento legal que possa garantir a continuidade das ações na sucessão das gestões municipais, efetivar a educação e cultura para o aperfeiçoamento do cooperativismo local e possibilitar a nomeação de gestores e servidores técnicos capacitados para desenvolver o cooperativismo local.

Quanto aos desafios e possíveis diretrizes para consolidação da gestão de política pública de fomento ao cooperativismo no município de Gurupi-TO, constata-se como desafios: a efetividade da política pública de fomento ao cooperativismo por meio de ações contínuas de educação e cultura cooperativista, manutenção de uma gestão pública dirigida por atores capacitados e comprometimento governamental e institucional para a consolidação de cooperativas rurais, em especial que abrange atividades de agricultura familiar.

No que tange ao objetivo que foi delineado este foi alcançado oferecendo subsídios para a resolução da problemática inicial (Quais os desafios e possibilidades da gestão de 
políticas públicas e do cooperativismo para sua consolidação no município de GurupiTO?)

Importante ressaltar que a política pública para o fomento do cooperativismo em Gurupi-To promove ações importantes para proporcionar a melhoria da qualidade de vida no meio rural especialmente aos pequenos produtores que desenvolvem suas atividades agrícolas em âmbito coletivo (assentamentos) e familiar, e enquanto membros de associações locais declararam na maioria das falas que conhecem o cooperativismo. Porém, a forma de organização e realização da produção são exercidos de forma manual com auxílio da gestão pública no incremento da produção e o trabalho intelectual é orientado pela organização a qual pertencem, caracterizando-se a autogestão e equiparando-se às cooperativas populares (CANÇADO, 2005).

No decorrer da pesquisa foi possível classificar as organizações dos beneficiários da política pública de fomento ao cooperativismo como classes populares menos favorecidas em situação de desemprego e exclusão social o que os agrega ainda mais à classe das cooperativas populares.

As ações públicas, desenvolvidas em prol dos beneficiários com o fornecimento de meios de produção, também constituem outro elemento que se faz presente nas organizações dos agricultores familiares.

A política pública analisada resgata o papel do Estado, no caso o município de Gurupi-TO, como indutor do processo econômico, impulsionador das respostas econômicas e sociais às reivindicações dos beneficiários, qual sejam, os agricultores familiares.

A gestão da política pública analisada enfatiza a criação direta de oportunidade de trabalho aos trabalhadores organizados propiciando a emancipação social garantindo cidadania e inclusão social.

Com estas considerações tecidas foi possível destacar elementos que podem contribuir para a consolidação da política pública de fomento ao cooperativismo em Gurupi-TO através da elaboração de diretrizes, objetivos e instrumentos capazes de desenvolver estratégias de gestão na condução da política pública existente com propósitos de implantação de recursos humanos capacitados que visam a melhoria da população rural que vivem da agricultura familiar.

Assim pode-se afirmar que apesar dos desafios elencados, o fomento ao cooperativismo promove relevante influência e possibilidade no processo de inclusão social não só na busca de crescimento econômico, mas também como fortalecimento 
social e político dos beneficiários da política municipal de fomento ao cooperativismo.

\section{REFERÉNCIAS}

AMABILE, A. E. N. Políticas Públicas. In: CASTRO, C. L. F.; GONTIJO, C. R. B.; AMABILE, A. E. N. (Org.). Dicionário de políticas públicas. Barbacena: EdUEMG, 2012.

BARDIN, L. Análise de conteúdo. Lisboa: Edições 70, 2016.

BARROS, E. F. Estratégias Metodológicas para Avaliação de Programas

Governamentais. In Anais do XI Congresso Brasileiro de Custos - Porto Seguro, BA, Brasil, 27 a 30 de outubro de 2004.

BOULLOSA, R. de F.; SCHOMMER, P. C. Gestão social: caso de inovação em políticas públicas ou mais um enigma de lampedusa. Encontro Nacional de Pesquisadores em Gestão Social, 2009.

BRASIL. Constituição da República Federativa do Brasil, de 05 de outubro de 1988. Disponível em <http://www.planalto.gov.br/ccivil 03/Constituicao/Constituicao.htm> Acesso em 28 Nov. 2017.

BRAÚNA, A. A. O papel do cooperativismo no desenvolvimento do estado do Tocantins. 2016.

CANÇADO, A. C. Para a apreensão de um conceito de cooperativa popular. Encontro anual da ANPAD, v. 29, 2005.

DIAS, R. Políticas públicas: princípios, propósitos e processos. São Paulo: Atlas, 2012.

DYE, T. R. Understanding Public Policy. Prentice-Hall, Englewood Cliffs, 1972.

ESTATUTO, DA TERRA. Lei nํ 4.504 de 30 de novembro de 1964. 2014.

FONTANELLA, Bruno José Barcellos; RICAS, Janete; TURATO, Egberto Ribeiro. Amostragem por saturação em pesquisas qualitativas em saúde: contribuições teóricas. Cadernos de saúde pública, 2008, 24: 17-27.

FREY, K. Políticas públicas: um debate conceitual e reflexões referentes à prática da análise de políticas públicas no Brasil. In Planejamento e políticas públicas, 2009.

GURUPI, Câmara Municipal. Lei municipal n.ำ 768 de 01 de maio de 1989.

GURUPI, Câmara Municipal. Lei municipal n.ำ 977 de 16 de julho de 1992.

GURUPI, Câmara Municipal. Lei municipal n.ำ1.188 de 30 de junho de 1997.

GURUPI, Câmara Municipal. Lei municipal n. 1.507 de 27 de junho de 2002.

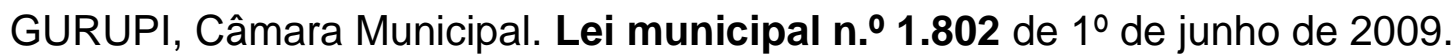

GURUPI, Câmara Municipal. Lei municipal n.ำ 1.852 de 04 de janeiro de 2010 .

GURUPI, Câmara Municipal. Lei municipal n. 2.078 de 25 de janeiro de 2013. 
GURUPI, Câmara Municipal. Lei municipal n. 2.152 de 30 de dezembro de 2013 .

GURUPI, Câmara Municipal. Lei municipal n. 2.188 de 30 de dezembro de 2014 .

HOWLETT, M.; RAMESH, M.; PERL, A. Política pública: seus ciclos e subsistemas-uma abordagem integral. São Paulo: Campus, 2013.

INSTITUTO BRASILEIRO DE GEOGRAFIA E ESTATÍSTICA - IBGE.

Brasil/Tocantins/Gurupi. Disponível em:

<https://cidades.ibge.gov.br/brasil/to/gurupi/panorama>. Acesso: 16 Jan. 2018.

JENKINS, William leuan. Policy analysis: A political and organisational perspective. London: M. Robertson, 1978.

LEOPOLDINO, C. J.; DE QUADROS, L. C.. O direito cooperativo e sua normativa jurídica. Revista Faz Ciência, v.13, n.17, p.185, 2011.

MANCE, Euclides André. A revolução das redes: a colaboração solidária como uma alternativa pós-capitalista à globalização atual. Vozes, 2000.

MILAGRES, C. S. F.; AMODEO, N. B. P.; SOUZA, D. N. Cooperativas e desenvolvimento de comunidades: promessas e decepções. Viçosa: Revista de C. Humanas, Ano XI, nํ1, 2011.

ORGANIZAÇÃO DAS COOPERATIVAS BRASILEIRAS - OCB. 0 cooperativismo brasileiro: uma história. Brasília, DF: Versão Br Comunicação e Marketing, 2004. Disponível em: < http://www.ocb.org.br/historia-do-cooperativismo. Acesso em 10 Jan. 2018.

PEREIRA, J. R. Gestão social de políticas públicas. Lavras: Ed. UFLA, 2011.

RUA, M. G.; ROMANINI, R. Para aprender políticas públicas: conceitos e teorias. Curso online políticas públicas, 2013.

SECCHI, L. Políticas públicas: conceitos, esquemas de análise, casos práticos. São Paulo: Cengage Learning, 2010.

SECCHI, L. Análise de políticas públicas: diagnóstico de problemas, recomendação de soluções. São Paulo: Cengage Learning, 2015.

SILVA, R. D. L.; PETARLY, R. R. Responsabilidade Social Empresarial no

Cooperativismo: O Dia de Cooperar como Estratégia de Voluntariado Cooperativista.

Coleção Tocantins Cooperativo. Palmas, Vol. II, p. 141-155, 2015.

SOUZA, C. Estado da arte da pesquisa em políticas públicas. In Políticas públicas no Brasil. Rio de Janeiro: Fiocruz, 2007, p.65-86.

SOUZA, C. Políticas públicas: uma revisão da literatura. Sociologias [online]. 2006, n.16, p.20-45.

TENÓRIO, F. G. Gestão social, um conceito não-idêntico? Ou a insuficiência inevitável do pensamento. In RIGO, A. S.; SILVA JÚNIOR, J. T.; SCHOMMER, P. C.;

CANÇADO, A. C. Gestão Social e Políticas Públicas de Desenvolvimento: Ações, Articulações e Agenda. 2010. 
THISSEN, W.A.H.; WALKER, W. E. Public Policy Analysis. Springer, 2013.

TOCANTINS, SECRETARIA DA AGRICULTURA E PECUÁRIA DO ESTADO DO TOCANTINS - SEAGRO-TO. Diretoria de fomento e fortalecimento ao cooperativismo e do associativismo rural. Palmas-TO: Seagro, 2013. 